\title{
Pneumonite Actínica Como Diagnóstico Diferencial Em Paciente Com Difícil Desmame Da Ventilação Mecânica: Um Relato De Caso.
}

\author{
Coelho, G.; Rocha, P.L.; \\ Apresentador: Germano Scheer Coelho
}

\section{Resumo}

Introdução: Doenças difusas do parênquima pulmonar pertencem a um grupo de patologias de evolução geralmente subaguda ou crônica, mas podem determinar insuficiência respiratória aguda, principalmente quando associadas à infecções concomitantes. A pneumonite actínica é uma condição que deve ser questionada em pacientes com alterações do sistema respiratório e que apresentem história prévia de radioterapia na região torácica.

Descrição do caso: Paciente de 63 anos, sexo feminino, branca, internou na unidade de terapia intensiva (UTI) devido à insuficiência respiratória aguda, com necessidade de intubação orotraqueal e ventilação mecânica. Era procedente do departamento de clínica médica, onde estava em tratamento para pneumonia comunitária grave. Como antecedentes patológicos, apresentava história de câncer de mama, sendo submetida à mastectomia há 9 meses, em tratamento com quimio e radioterapia desde então. Durante sua internação na UTI, apresentou melhora laboratorial, mas falhava em muitas tentativas de desmame da ventilação mecânica. Foi questionado cardiopatia como fator agravante do quadro pulmonar, no entanto esta hipótese foi afastada devido ao resultado normal do ecocardiograma. Foi solicitada, então, tomografia computadorizada (TC) de tórax, a qual evidenciou opacidades pulmonares, assumindo aspecto predominantemente em "vidro fosco", sendo presumido o diagnóstico pneumonite actínica com fibrose pulmonar. Foi iniciado corticoterapia sistêmica associada à fisioterapia respiratória, ocasionando melhora gradual do quadro clínico, obtendo-se sucesso do desmame da ventilação mecânica no $21^{\circ}$ dia de internação na UTI. Discussão: A pneumonite actínica caracteriza-se como uma complicação precoce da radiação torácica advinda da radioterapia realizada no tratamento de câncer de mama, podendo evoluir para fibrose pulmonar. A sintomatologia pode ser inespecífica, variando de dispneia e tosse, a infecções de repetição e insuficiência respiratória aguda. Este fenômeno pode ocorrer em até $15 \%$ de pacientes submetidos à radioterapia no tratamento de câncer de mama, sendo que as atuais técnicas de irradiação com campo restrito podem minimizar a ocorrência desta complicação. Ainda que o diagnóstico seja feito através de biópsia pulmonar, achados da TC de tórax são característicos e muitas vezes suficientes da elucidação do caso. Em casos sintomáticos severos ou com comorbidades associadas, o uso de corticoides sistêmicos pode ser considerado.

\section{Referência:}

Coelho, G.; Rocha, P.L.;. Pneumonite Actínica Como Diagnóstico Diferencial Em Paciente Com Difícil Desmame Da Ventilação Mecânica: Um Relato De Caso.. In: II Congresso Brasileiro de Medicina Hospitalar - II CBMH [= Blucher Medical

Proceedings, vol.1, num.5] São Paulo: Editora Blucher, 2014. p.62

DOI 10.5151/medpro-II-cbmh-059 